\title{
Designing a crisis management model in Iran's archival centers: Pre-crisis stage
}

\author{
Maryam Nakhoda ${ }^{a^{*}}$, Sedigheh Ahmadi Fasih ${ }^{b}$, Mohamad Reza Esmalili Givi ${ }^{a}$ and Fahimeh \\ Bab-ol Havaejic
}

${ }^{a}$ Assistant professor, Department of Information Science and Knowledge Studies, Tehran University, Tehran, Iran

${ }^{b}$ PhD student, Department of Information Science and Knowledge Studies, University of Tehran, Iran ${ }^{c}$ Associate Professor, Science and Research Branch, Islamic Azad University, Tehran, Iran

\section{H R O N I C L E}

Article history:

Received: November 26, 2017

Received in revised format: November 26, 2017

Accepted: January 18, 2018

Available online:

January 18, 2018

Keywords:

Archives

Grounded theory method

Pre-crisis management

\section{A B S T R A C T}

\begin{abstract}
The purpose of this research is to design a crisis management model in the archival centers of Iran during the pre-crisis phase. The present study was conducted with a qualitative approach using the Grounded theory method. The necessary data was collected using semi-structured interviews. Data saturation was a major factor in determining the sample size. The research population included 20 crisis management specialists and managers of archives in Iran and the data analysis was performed in three stages: open, axial, and selective coding. The paradigmatic model derived from the findings of the research includes the sections of the causal conditions, strategies, intervening conditions and the underlying conditions and their outcomes. The causal conditions are located in two categories of internal crises such as biological crises and lack of proper management, and external crises such as natural disasters, fires and human-made crises. Intervener conditions and backgrounds include categories such as lack of specialist staff training, lack of appropriate environmental conditions and management mechanisms, archival building and human resources issues. To prevent and mitigate the effects of the crisis in archives, some strategies are required such as modern education for resilience, teaching how to use documents, standardizing buildings and equipment (non-use of steel skeletons in building archives, use of concrete skeletons Armed or metal, as well as the use of walls and doors and floors of anti-fire covers) in the building of archives and the establishment of multi-layer protective systems for the protection of documents.
\end{abstract}

\section{Introduction}

Crisis Management is a process of planning, performance and executive action applied by some organizations, in order to identify and reduce the level of risk and managing of the coping operation, reconstruction and rehabilitation of the affected areas (Carr, 2012). By considering to the analysis of preindicators and available information resources, the main goal of this process is to avert from the existing crises by using existing tools, and in case it occurs, being prepared for reducing the amount of damages in various archival areas and bouncing back to the normal circumstances (Carr, 2012). Pearson and Claire (1998) argue that crisis management is a systematic effort by members of an organization and * Corresponding author.

E-mail address: ahmadifa_se@yahoo.com (M. Nakhoda) 
outsider stakeholders for preventing form possible crises and beneficial management at the time of occurrence. The cultural heritage centers, archives and libraries are exposed to natural and man-made perils; perils which damage resources and buildings. Any incident that threatens human security or any threaten that may result in destruction of the building, content, equipment or services of the archives is called; crisis of archives (Maula, et al., 2013; Şener, 2012). If we take a historical glance at the vulnerability of the archives, we can briefly mention some of the following:

The Alexandria Library in $200 \mathrm{BC}$ is the most famous historical example in this case, which was burnt and destroyed by street-warriors of the Kaiser Rhymes and city champions. Next. The American Library of Congress (Harris \& Schur , 2006) ) was burnt down by the British during the wars that began in 1812; the Florence Library in Italy (1966) was destroyed by flood. In addition, the conflagration of the Library of the Faculty of Literature and Humanities University of Isfahan in 2007 and the fire of the Law Library of Tehran University are other cases of crises. There is a classification of different kinds of threatens and crises in archives shown in Fig. 1.

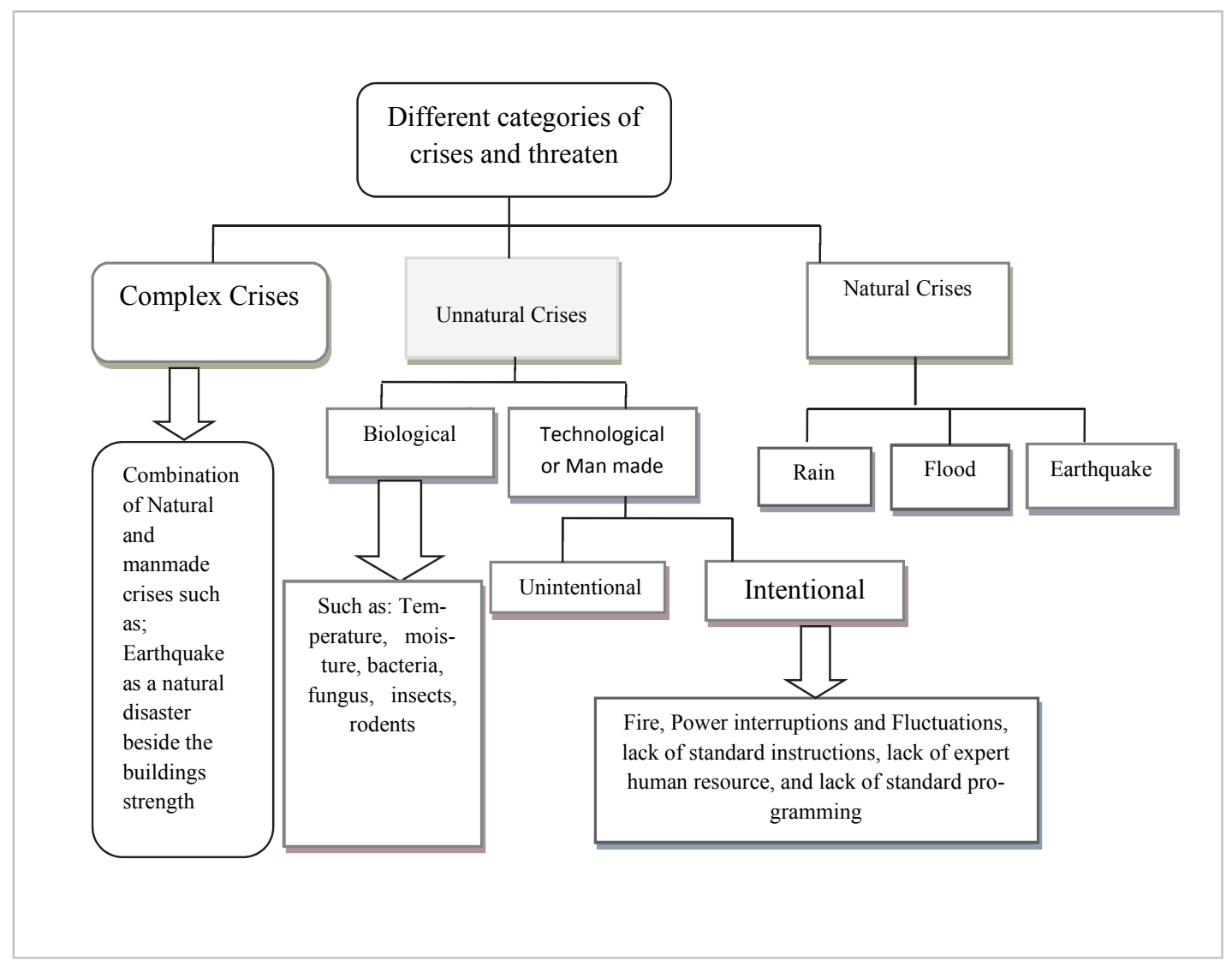

Fig. 1. Classification of Types of and Threats and Crisis in the National Archives of Iran

According to Hermann et al. (2006), crises is a disaster that makes people confused and dazed, undermines the power of an effective and reactive response, and compromises the fulfillment of their goals. However Perrow (1999), discriminates between the incident and the crisis. He describes the crisis as a major discrepancy, which, contrary to an incident, deprives the whole system from working and compromises the system and its lifetime with major problem. Several definitions of crisis management have been provided by researchers. Crisis management is a practical science that by a systematic observing and analyzing of the previous crises tries to find a powerful tool by which, on the one hand, it is possible to avert from the occurrence of catastrophes or being prepare for dealing with them, and on the other hand, in case of occurrence of a crisis, being prepared for provisioning assistance and improving the affected situation (Mosslemin et al., 2004). Any incident that threatens human security or any threaten 
that may result in destruction of the building, content, equipment or services of the archives is called crisis of archives. It is impossible to prevent from the occurrence of all kinds of crises but archives must plan for effective crisis management (Matthews \& Smith, 2016).

Due to the diverse, complex, ambiguous and multidimensional nature of the crisis, the crisis management is a complicated subject. Hence different experts have developed various models that help to simplify the complexity of crisis management process. Various models usually take different steps for the crisis management process, which can be divided into three categories: (1) pre-crisis measures (2) crisis measures (3) post-crisis measures. There have been some changes in our understanding of the crisis over the past five decades (Letukas \& Barnshaw, 2008) which have made us know a crisis as a specific social status that is created through a period of time and spatial extent rather than as an event which occurs at a particular time and place (Mitroff et al., 1989). These changes in our understanding of the crisis have made the pre-crisis stage more important. That is because, in the crisis management, crisis approach has been taken into consideration instead of anti-crisis approaches. In the crisis approach, crisis management, is to predict, prevent and prepare for dealing with possible crisis by adopting a supra-active approach in the pre-crisis phase (Coombs, 2016). In archives, as any organization, there is a possibility of the emergence and the occurrence of all signs of natural and organizational crises. Since, it is impossible to predict the exact time of occurrence of these catastrophes, it is necessary to plan for the identification, preparation and prevention in Iran's archival centers. Therefore, managers should continuously be prepared to deal with crises, and they must consider their organizations in order to evert or mitigate the effects of the crisis (Yaqin Lu \& Khalili Iraqi, 2004). Moreover, the existence of many perseverance in pre-crisis management, in areas such as urban transport, urban management, urbanization and civil engineering, health services, and library, etc., highlight the importance of addressing these subjects. According to Azizpour et al. (2011), Myer et al. (2007) and Mastaneh and Mouseli (2011), factors such as the lack of a human resources organization system, lack of training courses and the lack of use of modern technologies in libraries are known as hindrance of implementing a standard crisis management. Sanger (2012) also points to one of the management issues in organizations and concludes that so far strategic management theories have not been presented as a practical tool for dealing with the crisis, and generally, managers do not use strategic planning to deal with organizational crises, and this is a kind of deficiency in managers' performance. Mitroff et al. (1989) argue that many of the managers of organizations neither accept that they are in trouble with crisis, nor do they still justify themselves and their audiences with crisis. They consider this factor as an interfering factor in the implementation of crisis management in organizations. In the present study, the lack of understanding of archival crises by managers and their poor skills have been defined as an interfering subject in the management of the archives crisis. Farhoudi and Bab al-Hawaiji (2011) believe in that, values, human resources, methods and means are known as the basic and important principles of the crisis management in Iran's libraries. In addition, it encompasses the main issues such as paying attention to applicants' personality and traits during recruitment, using modern methods to enrich skills such as; human communication, ability of preventing activities and standardization of the construction of libraries.

\section{Methodology}

This research is a qualitative and corpus based study. This is a general research to product theories, and it is based on the collected data and systematically analyzed during the research process (Strauss \& Corbin, 1998). The present study consisted of crisis management specialists and managers of archives in Iran. At first, 20 crisis management specialists and managers of Iran's archives were identified, but four of them did not participate in the interview. There were enough interviews with the community members and the rest of interviews with the other people did not add anything new to the previous data. Finally, 16 interviews were conducted by the researchers. In this research, a semi-structured interview was conducted and in-person interview was used to collect the data. Interviews were recorded. In this interview, the interview questions are predefined and all respondents will be asked similar questions; 
however, they are free to answer their answers in any way they prefer to answer. Of course, the details of the interview are not mentioned in the interview guide. These parts of interview were determined during the interview process (Taylor et al., 2015). There were 16 initial questions and all of them were arranged according to previous studies that were focused on this area, and also according to Mitroff et al. (1989), which deals with the three stages of the crisis. The final interview questions included 10 open questions that were asked in primary steps. During the interviews, according to the articles provided by the interviewees, more questions were asked by the researchers to develop the subject. The length of the interview was about 45 to 60 minutes depending on the response rates.

After finishing every interview, by using Word software, audio files and notes of the investigator during the interview, were converted into text files in separate files, and then all of data were analyzed. For using the data analysis steps, the corpus based study emphasizes on the theoretical coding, which consists of three stages of open, pivotal, and selective coding. The first stage is open, and defined as an analytical process in which identifies the concepts, features, and dimensions which are discovered in the data (Strauss \& Corbin, 1998). The second step is axial coding, in fact, the process of connecting categories is called sub-category, because the axial coding concentrates on a category that links the categories to the level of attributes and dimensions. The third stage of coding is selective coding. This type of coding is defined as the process of integrating and refining the categories and, finally, the supply of theories. The main category (core category) is the main topic of this research (Strauss \& Corbin, 1988). As a matter of fact, this stage is a theoretical explanation of the process that has been studied. This is the theoretical explanation of the crisis management process in the archives, which has been achieved through the formulation of the relationship between the categories. In order to explore the categories and their characteristics, in addition to the extracted concepts, the categorization of core concepts and concepts were put into Table 1. Different criteria for validating the qualitative research have been presented by researchers. To assess the validity and reliability of the data in the qualitative section, four criteria were used which all of them were also presented by Lincoln and Guba (1985).

\section{Table 1}

\begin{tabular}{|c|c|c|}
\hline Concepts & Categories & Core concept \\
\hline $\begin{array}{l}\text { Considering the heating system, consider- } \\
\text { ing the air conditioning system, lack of re- } \\
\text { placement filters, the HVAC system }\end{array}$ & $\begin{array}{l}\text { 1. Considering the heating system. } \\
\text { 2.Considering the air conditioning system } \\
\text { 3. Prediction the archival building equip- } \\
\text { ment. }\end{array}$ & Predicting the building equipment. \\
\hline $\begin{array}{l}\text { Lack of a comprehensive crisis plan for re- } \\
\text { constructing documents, unplanned sched- } \\
\text { uling for document rebuilding, lack of in- } \\
\text { structions for document reconstructing. }\end{array}$ & $\begin{array}{l}\text { 1. Lack of a comprehensive plan a compre- } \\
\text { hensive crisis plan to reconstruct docu- } \\
\text { ments. } \\
\text { 2. Lack of a documented plan to recon- } \\
\text { struct documents. }\end{array}$ & $\begin{array}{l}\text { Lack of comprehensive crisis plan for re- } \\
\text { constructing documents. }\end{array}$ \\
\hline $\begin{array}{l}\text { Standardizing the building against fire, an- } \\
\text { ticipating the fire protection layers of the } \\
\text { building, using anti-fire or waterproofing } \\
\text { layers to rebuild the building against fire. }\end{array}$ & $\begin{array}{l}\text { 1. Standardizing the building against fire. } \\
\text { 2. Predicting the fire protection layers of } \\
\text { the building. }\end{array}$ & Standardizing the building. \\
\hline
\end{tabular}

For the present study, for ascertaining the reality and reliability of the collected data, the researchers had a continuous attendance in the research environment and also the audio files of the interviews were reviewed and if there was any ambiguity in the answers, the interviewees were questioned again. It was also tried to accurately record all steps of the research and all findings and taken decisions were consulted and discussed with the supervisor and professors. For translatability, this research refers to the degree of generalizability or transferring of results to other contexts and environments. In order to fulfill the expound criteria which is one of the most important criteria for transferability, all results are presented with accurate elaborations. In this study, in order to ensure the reliability and the feasibility of the research, and also to provide suitable circumstances for investigation of outsiders, all decisions, details, interpretations and analyzes were registered during the process of research. Finally, for verifiability of the present research, all the documents related to the research data as well as the inferences, 
interpretations and findings were systematically recorded by the researcher. All steps of conceptualization and categorization were taken from the documentation of the interviews and tried to avoid any bias. On the other hand, all coding steps were first reviewed by the supervisor and professors (NikbakhtNasrabadi et al., 2012). Another important point is the reliability and validity of the categories derived from the text of the interview note, which was calculated by Cronbach's alpha. The reliability means how much it is tangible to others, for this purpose, in addition to the researcher, categorization from the primary extracted components, were encoded by another encoder (by selecting 28 of the notes related to the texts), and then Krippendorff's alpha was calculated to determine the reliability, in which the Krippendorff's alpha in the range of 28 texts have been analyzed. It showed a figure about 0.89 in the pre-crisis management categories indicating the acceptable reliability (the least expected reliability coefficient is 0.80 in the Krippendorff's alpha). Online recal compiler ${ }^{1}$ has been used to calculate Cronbach's alpha.

\section{Data analysis}

The analysis of the data derived from the interview was carried out in three stages of open, axial and selective coding.

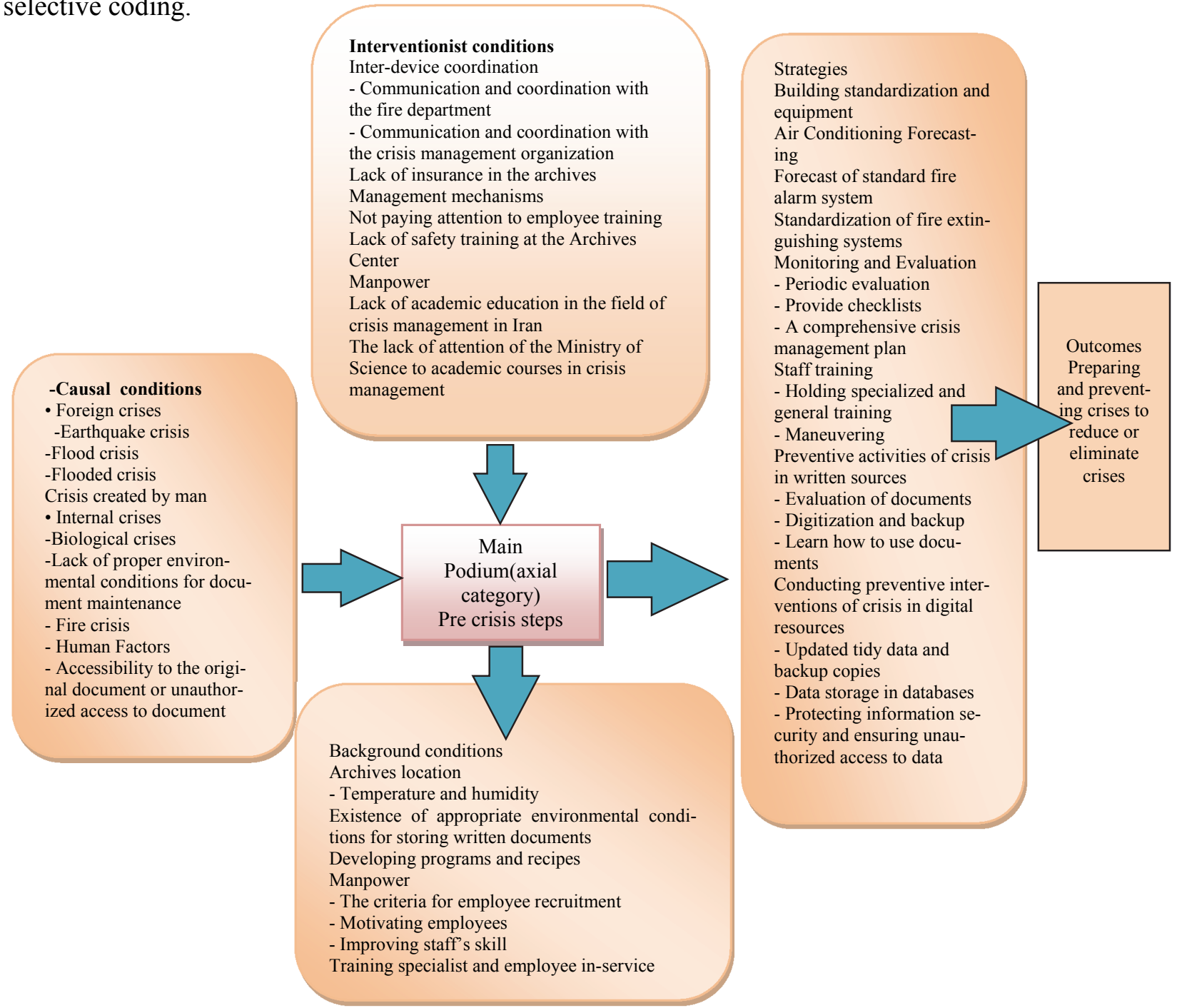

Fig. 2. Pre-crisis management model in Iran's archival centers 
In the open coding, data analysis was carried out in a micro-to-micro and a row-to-line method. After abstracting the concepts from the propositions, they were compared and then, related concepts have been integrated into a more general concept as a general title that is; category. In order to discover the categories and their features, in addition to the extracted concepts, the categorization of concepts and concepts of the core, were entered into a table (Fig. 1). In the central coding, the main categories were identified and then the causal conditions, the underlying conditions and mediating conditions, the strategies and the consequences were determined. This step involves drawing a shape in which the coding chart or paradigmatic model of the research was presented. This graph shows the relationship among causal conditions, strategies, intervening conditions, and background and outcomes. In fact, Fig. 2 shows the pre-crisis management model in Iran's archival centers in the pre-crisis phase. The central axis or central phenomenon is the main issue of the present study.

As it has been shown in the Fig. 2, the main topic of our research is pre-crisis management in Iran's archival centers which is placed at the middle of the diagram as a starting point. The causal condition has been linked to the main category via a one-way arrow, which means that the existing adverse conditions in the archives have led to the formation of the main category of research. Fields and interventionist factors have also been linked to the main category via a one-way arrow, indicating that these two categories, along with their subcategories in the archives, affect the main subject. Indeed, if these two categories and their subcategories in the archives are carefully observed and applied by managers and employees, they will have a positive impact on the crisis management and vice versa. The main issue (podium) is linked to the strategies, indicating that, in order to attain the key outcome of crisis management of archives, some strategies and actions should be observed in archives. This part has also been linked to the outcome via a one- way arrow.

According to the presented background pattern, which is based on the use of data analysis of the interviews, the causal conditions which brought about the need of a standard crisis management and also the main issue of this research, are known as internal and external crises which can cause various adverse conditions in archives. These kinds of crises have their specific features and subcategories. The interviewees pointed to factors such as; natural disasters (floods, rains and flooding), human factors, fires, and biological crises as examples of external and internal crises. The resultant information from interviewees about natural disasters (rain crisis, storm crisis, and flood crisis) that are sub-categories of external crisis indicate that, natural disasters such as flood, rain, and water are the first and the main crisis which archives have confronted with. Due to the lack of appropriate standardization of buildings some archives and buildings have faced with these crises. To avert from flood and flooded crisis, the interviewees also put an emphasis on the flood prevention. They believe that, archives must be constantly in touch with the relevant organizations and flood crises to keep the archives regularly in contact with the relevant organizations and they should transfer documents to cold stores, in case of flood or flooded crisis, to know about the existing cold stores in the country. These findings are consistent with part of Kuligowski and Mileti (2009) studies on the flood crisis. The resultant information from the interviewees about the earthquake crisis which is considered as a natural disaster indicate that there hasn't been any destruction of archival centers in Iran by the earthquake crisis. Most interviewees put an emphasis on the preventing from the earthquake crisis risks and also argued that the first step in this area was standardization and retrofit of the archival buildings, and the more specialized archive buildings are built according to the standards, the more they will be capable to reduce the possibility of demolition of the building and the destruction of the documents at the time of the earthquake. Hence, they emphasized on the use of the patterns and standards of other archival buildings and the use of other experiences in this field for future construction. We can refer to Guan et al.'s (2011) studies on the earthquake crisis. This approach exists in our interview.

The resultant information from the interviewees on the fire crisis indicate that many interviewees believed that many workers could not be able to protect the documents during the fire. Security and safety of the people at the site was the first priority of this crisis. Staffs and users have to evacuate and leave the site, then, if it is possible, they have to transfer the prioritized documents and rare sources to a 
secure place that has already been identified. This approach has also been mentioned in Roper et al. (1999) studies.

Also, in the category of crisis, biological factors are considered as the most important internal crisis in archives. The findings from the interview indicate that molds and fungi are the most reported biological factors in the archives. Poor environmental conditions for the storage of documents, the lack of standard air conditioning systems, and high Humidity in the reservoir have led to overgrowth of various fungi and mildew. The findings of this study are consisted with Mohsenian (2009) theories. They argue that the activity and growth of insects and microorganisms are one of the major and most common causes of the destruction of paper resources. If the humidity and heat of the environment are not at the standard level, suitable conditions for the growth of these destructive factors will be provided.

Also, based on this resultant pattern, factors such as; the mechanisms for inter-agency coordination, the lack of attention to insurance in the archives, can either directly or indirectly interfere in the implementation of crisis management activities in the archives. The interviewees introduced some indices and categories which are related to these mechanisms. In the context of inter-institutional coordination, the findings from the interview indicate that the archives are only coordinating with the fire department and the crisis management organization, which communicates with crisis management specialists to identify the crisis areas from archival centers. They also deal with firefighting in the field of crisis management training and the use of fire extinguishing systems, and they are also in the process of crisis planning and have coordinated the field. Also, the interviewees mentioned some factors such as; the weakness of the coordinating agenda and the overlapping of the responsibilities of organizations, the lack of unity in managing and also, indefinite authority of organizations. We can refer to Adekanye (2011) studies about this field.

The findings of the interviewees show that many archival centers in Iran do not have insurance coverage, which was due to the high cost of insurance, and believed that this high cost would cause less attention to the insurance of archives. And finally, because of the importance of documents and resources and their high values, they emphasized on the urgency and necessity of insurance in the archives. They also demanded the government to reduce the premium for archives. They believe that, the reduction of premium indicates, the consideration and attention of government to the crisis-planning programs in the archives and also it would indicate that the preventive measures had been taken. Approach of this research is consisted with Eden and Matthews (2016) studies.

In the managerial category, we have pointed to the weaknesses of managers' skill in making decisions and policies, some personality traits of managers, and their inadequate understanding of crisis factors. Also, some of the contributors in the interview described archival expertise as the most important criterion for selecting managers.

For the latter case, some interventionist factors such as; the lack of attention to the training of employees, including specialized training in the field of archival crises, lack of attention to modern education (resilience), lack of maneuver, lack of complete and adequate training, lack of attention to training of human resources, and the lack of attention to academic education in the field of crisis management in Iran were other important factors. These interventionist factors have been identified as an obstacle to the training of archival centers. Finally, interviewees demanded for institutionalization of security education in Iran.

The proposed model shows that the predominant areas and sub-domains of the crisis management in the archives are classified in indicators such as the existence of appropriate environmental conditions for document storage, programming, archive location, and manpower. The interviewees are referred to factors that influenced the implementation and speed of the crisis management process. Interviewees reported various indicators and categories. For the category of environmental factors which include the internal crisis of archives, they referred to some subcategories as; temperature and humidity crises in 
the archives. They believed that if temperature and humidity were not controlled in the archives, they would be exposed to relative humidity and temperature fluctuations, and consequently it would result in fragility, shrinkage, loosening, and also a reduction of the quality of documents and ultimately loss of documents. The participants also pointed to the amount of temperature and humidity in the building according to the standards. The average humidity in the course of one year was $50 \%$ with a minimum oscillation and a temperature of one year: $18^{\circ} \mathrm{C}$ with a minimum fluctuation. The findings of the present study are consisted with some parts of Trinkaus-Randall et al. (2014) studies on the standard of temperature and humidity in archival stashes.

In the programming and guidelines, the findings of the interview indicate, the lack of attention to the programmed crisis management, and only some archival centers try to take a step toward developing a planned management in the form of written and coded instructions. Also, interviews with the managers of archival centers showed that the design and development of crisis management programs in the archives was emphasized to the pre-crisis stage, in which some factors such as; Pinpointing the causes of the crisis, prioritizing according to the goals of the archive, sufficient information from the building, creating a crisis management team, and training of human resources, were observed. The findings of the present study are consisted with the studies of Adekanye (2011) studies on crisis programs. They argue that, prevention from crisis is the most important aspect of planning, because this part of the program includes all parts of the conservation and preservation program.

The findings of the research showed that the majority of archival centers did not care about the location of archive buildings. Buildings of some archival centers were placed on some adverse areas such as; on the fault, underground water, on the earthquake line and subway lines, and also on the highways. They also believed that the choice of location for the archival building was a vital matter. Many of the mistakes can be corrected later, but, if the place of archive buildings were chosen wrongly, it would not be compensable and may endanger the future of the archive. This approach is consistent with findings of Dadson's (2012) studies.

In the case of human resources, interviewees also stated that in employing and employing manpower, personality traits and their skills should be extremely considered, and after recruiting, staffs' skills would be enriched by conducting training classes. They argued that human resources are critical at levels such as; inhibition and resolution of the crisis, and the provision of appropriate rewards can directly in motivate the workforce. They also mentioned some negative factors such as; the employee's reluctance and impoliteness, the lack of specialized training, including the lack of use of modern training (resilience), lack of training on how users use documents, access to the document's original or unauthorized access to documents, and lack of performing maneuvers. They also believed that employees have an important role in protecting documents and they can prevent from any documents theft by placing security gates. They also consider the presence of experts in archives as the most important and influencing factors in the crisis management. This finding is consistent with some sections of Myer et al. (2007) and Pricop's (2012) studies on recruitment and training of human resources.

In order to integrate the pattern, the researcher considers some strategies and actions that archives should observe and use them to manage the pre-crisis stage properly. The results indicate that the assessment and identification of crisis areas, standardization of buildings and equipment, air conditioning forecasting and standard fire detection and fire alarm systems, training the staff, conducting crisisprevention activities in written and digital sources were identified as the main strategies.

The interviewees stated some sub-categories. According to the findings of interviews, In the evaluation category, two types of evaluation are carried out in the archives: (1) A periodic evaluation of activities which must be observed per six months, including first aid kits, fire extinguishing and fire alarm systems, and non-structural components of the site to determine their resistance to earthquakes. (2) To measure the readiness of the archives against potential crises, some checklists are developed, and the team assessment team (Commander of the incident) can use them to assess the readiness of the archives 
to deal with a crisis. These checklists must be complied at least once a year, which may include a building and equipment checklist, a water assessment checklist, electricity and gas assessment checklist, a staff assessment checklist and a document evaluation checklist, etc. Finally, after evaluations, these checklists we need to create a crisis map and it can be used in the time of occurrence. These findings are consisted with the standards of the American Fire Association (2012) studies. In the category of building standardization and equipment, the findings from the interview indicated that most of the interviewees believed that many of our archival facilities did not comply with the archival building standards and due to this matter, the majority of archival centers are not properly designed and they are not substantially constructed and therefore do not have sufficient strength. According to interviewees, few archives, comply with standards and factors such as; building safety against earthquakes (8 magnets), building resistance to fire, non-piped gas in the building. Other results from the interview also indicated that, design and construction of the archive building is the most important and critical point in predicting the crisis. The main structure of the archival building, especially the document resources, must be metal or concrete. Another principle in designing and constructing the building is the use of fire proof walls and doors and floors. Finally, the interviewees believed that having a well-equipped building would solve some of the problems that threaten the documents. Since the reservoir is the most important part of an archive, it should be carefully constructed. These findings are consisted with some parts of Azizpour (2011) studies. And in the air conditioner prediction section, the results of the interviews indicate that, all archives are equipped with all heating, air conditioning and air conditioning systems (HVACs) for emergencies in the reservoirs, but in some archives they are not appropriately controlled in the reservoirs and the filters are not regularly replaced.

The heating system is more active and is regularly updated. The findings of this study are consisted with some parts of Hughes and O'Brien (2006) studies on the heating and air conditioning systems. In the category of prediction of the announcement and fire detection system, the findings of the interviewees indicate that the estimated equipment for the crisis in the reservoirs are: (1) an announcement and firefighting system (2) CCTV cameras to observe specific movements (3) Designing a mechanized system for testing temperature and humidity from (remote), (4) some fire extinguishers which used gases such as (co2, fm 200) were installed in reservoirs and floors. Participants considered fm200 as the most suitable gas for fire extinguishing in archives, and believed that other gases, such as co2 and halon were dangerous, for example, co2 was harmful for workers or halon gas that depleted ozone layer. Finally, they advised archives to get standard equipment from archives which comply with standards. This part of our study in consisted with the American Fire Standard (2012).

In the category of staff training, interviewees referred to short- and long-term trainings that are held in a specialized and general manner. Specialized training encompasses firefighting training subcategories, document maintenance, document protection and maintenance, first aid training and modern training on resilience, maneuvering, creating a crisis management team to prepare a crisis map, and in the public sector, theoretical training of crisis management and conducting service classes. Also, the findings from the interview showed that these trainings are not sufficient for employees, because the training is dedicated only to a brief part of the specialized training, and many of the trainings which are crucial for the staff are not taken into account, and some parts of training are not up to date. The present study is in consisted with some parts of Myer et al. (2007) studies.

Of the other necessary guidelines, the preventive activities of the crisis in written and digital sources are such factors which, every interviewee emphasized on. They also referred to data and backup copies, training users to use documents, and finally prioritizing documents to transfer them during the crisis out of the archive.

Finally, to protect the documents, participants argued that, archives must restrict the people's access to important documents. In addition to standardization of buildings and equipment, interviewers emphasized on critical factors such as; observing environmental factors under the categories such as providing a backup and maintaining them in several layers of protection outside of the archives, planning for the 
protection and safety of digital documents, constant checking and controlling electricity and electronic devices, having an electrical power control device, storing information simultaneously in two separate locations for the protection and safety of digital resources, reducing the space between storage to prevent data loss at the time of the crisis. Eventually importance of providing validity for crisis prevention in digital resources has been emphasized.

\section{Discussion and conclusion}

In this research, a model for pre-crisis management in Iran's archival centers was presented in the precrisis phase (Fig. 2), which consists of six sections including the main axis, causal conditions, fields, strategies, interveners and outcomes. As a matter of fact, an appropriate opportunity for implementation of crisis management will be provided, if archival managers observe factors such as; human resource issues, including staff training and recruitment criteria (personality traits, communications, and skills), and if they conduct and set programs and guidelines and choose an appropriate location of the archive building. On the other hand, interventional factors should be under control of crisis management, including lack of standards in archive building and equipment, lack of appropriate environmental conditions and also lack of inter-device coordination and denial of the implementation of crisis management. For the proposed model, the main category was related to the strategies. We need to take the necessary strategies and actions in the archives to achieve the main result of crisis management in the archives, which has the same consequences. The results have also indicated that evaluating and identifying areas of crisis in different areas, standardizing buildings and equipment, using crisis prevention methods in written and digital sources are the appropriate strategies for crisis management in archives. According to the proposed model, the consequence of using crisis management in archives with all the aspects presented is to reduce or eliminate the crisis in the Iranian archival center.

\section{Acknowledgement}

The authors would like to thank the anonymous referees for constructive comments on earlier version of this paper.

\section{References}

Adekanye, E. A. (2011). Insurance Coverage in Nigerian academic libraries, 1-6.

Azizpour, M., Zangiabadi, A., \& Esmaeilian, Z. (2011). Prioritization factors in urban disaster management, a case study organizations in disaster-related crisis in Isfahan. Journal of Geography and Environmental Planning, 43(3), 25-8.

Carr, N. (2012). The crisis in higher education. Technology Review, 115(6), 32-40.

Coombs, W. T. (2014). Ongoing crisis communication: Planning, managing, and responding. Sage Publications.

Corbin, J., \& Strauss, A. (2008). Basics of qualitative research: Techniques and procedures for developing grounded theory. Thousand Oaks.

Dadson, E. (2012). Emergency planning and response for libraries, archives and museums. Facet Publishing.

Farhoudi, F., \& Babalhaveaji, F. (2015). Indigenous pattern of crisis management in Iranian libraries: Qualitative research. Quarterly Journal of Information Research and Public Libraries, 21(3), 449466.

Guan, Y., Cheng, X., \& Zhang, Y. (2011). Study on the earthquake disaster reduction information management system and its application. International Journal of Intelligent Systems and Applications, 3(1), 51.

Harris, K. E., \& Schur, S. E. (2006). A brief history of preservation and conservation at the library of congress. In Library of Congress, www. loc. gov/preserv/history/careamer. html (accessed September 21,2010$)$. 
Hermann, J., Spandler, C., Hack, A., \& Korsakov, A. V. (2006). Aqueous fluids and hydrous melts in high-pressure and ultra-high pressure rocks: implications for element transfer in subduction zones. Lithos, 92(3), 399-417.

Kuligowski, E. D., \& Mileti, D. S. (2009). Modeling pre-evacuation delay by occupants in World Trade Center Towers 1 and 2 on September 11, 2001. Fire Safety Journal, 44(4), 487-496.

Letukas, L., \& Barnshaw, J. (2008). A world-system approach to post-catastrophe international relief. Social Forces, 87(2), 1063-1087.

Lincoln, Y. S., \& Guba, E. G. (1985). Naturalistic inquiry (Vol. 75). Sage

Mastaneh, Z., \& Mouseli, L. (2013). Capabilities and limitations of crisis management in the teaching hospitals of Hormozgan University of Medical Sciences, 2010. Scientific Research and Essays, 8(26), 1196-1202.

Matthews, G., \& Smith, Y. (2016). Disaster management in archives, libraries and museums. Routledge.

Maula, M. V., Keil, T., \& Zahra, S. A. (2013). Top management's attention to discontinuous technological change: Corporate venture capital as an alert mechanism. Organization Science, 24(3), 926947

Mitroff, I. I., Pauchant, T., Finney, M., \& Pearson, C. (1989). Do (some) organizations cause their own crises? The cultural profiles of crisis-prone vs. crisis-prepared organizations. Industrial Crisis Quarterly, 3(4), 269-283.

Mohsenian, S. (2009). Report of the Conference on Preventive Protection Training in Archival Collections. Ganjineh Documentation, 19(2), 68-69

Mosslemin, M. H., Yavari, I., Anary-Abbasinejad, M., \&Nateghi, M. R. (2004). Reaction between tertbutyl isocyanide and 1, 1, 1-trifluoro-4-aryl-butane-2, 4-diones: Synthesis of new trifluoromethylated furan derivatives. Journal of fluorine chemistry, 125(10), 1497-1500

Myer, R. A., Conte, C., \& Peterson, S. E. (2007). Human impact issues for crisis management in organizations. Disaster Prevention and Management: An International Journal, 16(5), 761-770.

Nikbakht-Nasrabadi, A., Mohammadpour, A., Abbasi, M., \& Javadi, M. (2012). Iranian nursing students perspective of their rights in clinical evaluation: A thematic analysis study. Life Science Journal, 9(4).

O'Brien, G. (2006). UK emergency preparedness: a step in the right direction?. Journal of International Affairs, 59(2), 63-85.

Pearson, C.M., \& Claire, J.A. (1998). Reframing crisis management. Academy of Management Review, 23(1), 58-76.

Perrow, C. (1999). Organizing to reduce the vulnerabilities of complexity. Journal of Contingencies and Crisis Management, 7(3), 150-155.

Pricop, O. C. (2012). Critical aspects in the strategic management theory. Procedia-Social and Behavioral Sciences, 3(28), 98-107.

Roper, M., Millar, L., \& Thurston, A. (1999). Managing public sector record. A Study Programme, 4647.

Sanger, D. E. (2012). Iranians Offer Plan to End Nuclear Crisis. The New York Times, 5.

Şener, İ. (2012). Strategic responses of top managers to environmental uncertainty. Procedia-Social and Behavioral Sciences, 3(28), 169-177.

Strauss, A., \& Corbin, J. (1998). Basics of qualitative research techniques. Sage publications.

Taylor, S. J., Bogdan, R., \& DeVault, M. (2015). Introduction to Qualitative Research Methods: A Guidebook and Resource. John Wiley \& Sons

Trinkaus-Randall, G., Reilly, J., \& Ford, P. (2014). The Massachusetts experiment: The role of the environment in collection preservation. The American Archivist, 77(1), 133-150.

Yaqin Lu, M., \& Khalili Iraqi, M. (2004). Crisis and crisis management - Examining the positive and negative effects of crisis in organizations, Tehran: Tadbir, 145, 62. 


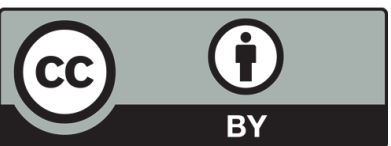

(C) 2018 by the authors; licensee Growing Science, Canada. This is an open access article distributed under the terms and conditions of the Creative Commons Attribution (CC-BY) license (http://creativecommons.org/licenses/by/4.0/). 